\title{
A Composite Target Concept for Multi-Pulse Radiography
}

\author{
J. McCarrick
}

This article was submitted to $14^{\text {th }}$ International Conference on High-Power Particle Beams, Albuquerque, N.M., June 23-28, 2002

\section{June 4, 2002}

U.S. Department of Energy

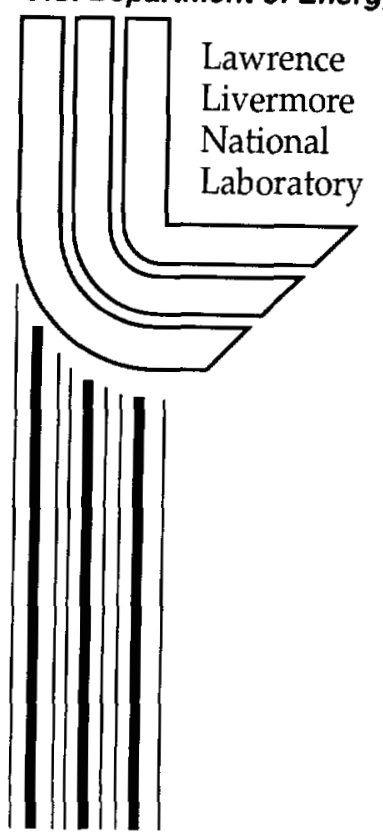




\section{DISCLAIMER}

This document was prepared as an account of work sponsored by an agency of the United States Government. Neither the United States Government nor the University of California nor any of their employees, makes any warranty, express or implied, or assumes any legal liability or responsibility for the accuracy, completeness, or usefulness of any information, apparatus, product, or process disclosed, or represents that its use would not infringe privately owned rights. Reference herein to any specific commercial product, process, or service by trade name, trademark, manufacturer, or otherwise, does not necessarily constitute or imply its endorsement, recommendation, or favoring by the United States Government or the University of California. The views and opinions of authors expressed herein do not necessarily state or reflect those of the United States Government or the University of California, and shall not be used for advertising or product endorsement purposes.

This is a preprint of a paper intended for publication in a journal or proceedings. Since changes may be made before publication, this preprint is made available with the understanding that it will not be cited or reproduced without the permission of the author.

This work was performed under the auspices of the United States Department of Energy by the University of California, Lawrence Livermore National Laboratory under contract No. W-7405-Eng-48.

This report has been reproduced directly from the best available copy.

Available electronically at http://www.doc.gov/bridge

Available for a processing fee to U.S. Department of Energy

And its contractors in paper from

U.S. Department of Energy

Office of Scientific and Technical Information

P.O. Box 62

Oak Ridge, TN 37831-0062

Telephone: (865) 576-8401

Facsimile: (865) 576-5728

E-mail: reports@adonis.osti.gov

Available for the sale to the public from

U.S. Department of Commerce

National Technical Information Service

5285 Port Royal Road

Springfield, VA 22161

Telephone: (800) 553-6847

Facsimile: (703) 605-6900

E-mail: orders@ntis.fedworld.gov

Online ordering: http://www.ntis.gov/ordering.htm

OR

Lawrence Livermore National Laboratory

Technical Information Department's Digital Library

http://www.llnl.gov/tid/Library.html 


\title{
A Composite Target Concept for Multi-Pulse Radiography
}

\author{
James McCarrick \\ Lawrence Livermore National Laboratory, PO Box 808, L-645, Livermore, CA 94551 USA
}

\begin{abstract}
Multi-pulse radiographic accelerators, such as the DARHT-II facility under construction at Los Alamos National Laboratory, generate $X$-rays by striking a solid, high-Z "bremsstrahlung converter target" with a tightly focused, high-current, relativistic electron beam. In the process, the converter target is heated to a plasma state and significant thermal expansion can occur during the interval between pulses, depleting the beam focus region of target material and reducing the X-ray output. Beam scatter and various other technical constraints prevent using thicker targets, moving the electron beam to a fresh target region, or moving fresh target material into a fixed beam location. The remaining possibility is to optimize the choice of target material to maximize the effective heat capacity while maintaining dose and minimizing scatter. A kinematic model of a "composite target" of high- $Z$ material in a low-Z matrix is presented here as a candidate for such an optimized target. The thermal destruction of the target cannot be avoided but can be slowed sufficiently to maintain the necessary output dose. Methods of manufacturing such targets, and their radiographic performance, are being tested at the ETA-II accelerator facility at Lawrence Livermore National Laboratory.
\end{abstract}

\section{INTRODUCTION}

Radiographic accelerators are used as transmissive X-ray diagnostics in high density, fast timescale hydrodynamic experiments. X-ray production is via bremsstrahlung from a high-current, relativistic electron beam striking a solid, high atomic number ("high Z") "converter target." The converter target on most existing single-pulse machines is simply a piece of refractory metal such as tungsten or tantalum. Unfortunately, the introduction of multi-pulse accelerator facilities such as DARHT-II at Los Alamos National Laboratory [1] precludes such a simple target system. A single beam pulse deposits enough energy into the converter material to raise its temperature to order 1 electron volt $(\sim 11600 \mathrm{~K})$, into a plasma state. The resulting thermal expansion is slow on the timescale of a single accelerator pulse $(\sim 50$ ns) and unimportant in the operation of a single pulse machine. However, the expansion is significant relative to the interval between pulses ( $\sim 500 \mathrm{~ns})$ on a multipulse machine. Radial expansion lowers the integrated line density of target material in the electron beam focal region, lowering the X-ray output (dose).

Without any additional constraints, there are numerous ways to maintain dose. The most obvious is a thicker target, so that enough material remains even after several pulses. More subtle is to use a dynamic target, replenishing material in the focal region between pulses; or to move the electron beam to a fresh location on a stationary target. 
However, a thicker target increases scattering of the electron beam and resulting X-ray spot size, lowering the resolution of the system. A moving target requires fast conversion of a significant amount of stored energy to achieve the required replenishing rate. Moving the beam has its own technical challenges and also changes the radiographic axis of the system. The remaining choice is optimize the target material itself to absorb as much energy as possible without expansion.

\section{BASIC REQUIREMENTS}

There are two basic constraints on the choice of target material. The most obvious is that there must be enough high-Z material present to generate sufficient $\mathrm{X}$-ray dose. The second is that the scattering of the electron beam in the target must be low enough that the system resolution is maintained. We wish to add to these some measure of "thermal strength." Let us use a highly simplified material model that lumps heat capacity, all energies associated with phase changes, and perhaps ionization energies into a single quantity we will call "the bonding energy," $E_{B}$. We will define it as the amount of energy per atom to go from fully bound in a solid lattice to completely unbound, in a material at constant volume (heating takes place much faster than any expansion). $E_{B}$ can be estimated by integrating over experimentally determined equations of state, and it does not vary dramatically for different materials on a peratom basis. Other studies looking to optimize materials for beam interactions $[2,3]$ did not find any naturally occurring compounds that had major advantages.

The idea we propose is to "custom build" a material by creating an artificial ratio of high- to low-Z material. The high- $Z$ material generates $X$-rays and, as a side effect, absorbs energy from the electron beam. The low- $Z$ material serves as a "reservoir" of bonds to be broken before the material can undergo thermal expansion, without contributing much to energy deposition or beam scatter (or, unfortunately, dose). One needs to transfer the energy from the high- $Z$ material to the low $-Z$ as fast as possible. Radiative transfer is not important at these timescales and temperatures. For conductive heat transfer to occur, we want the diffusion time of heat across the high- $Z$ material to be on the same timescale as a beam pulse. For a material such as tungsten, the diffusion length $\mathrm{d} \sim(\kappa \tau / \rho \mathrm{Cp})^{1 / 2} \sim 2$ microns, where $\kappa$ is the thermal conductivity $(\sim 170 \mathrm{~W} / \mathrm{m}-\mathrm{K}), \tau$ is the pulse length $(\sim 50 \mathrm{~ns}), \rho$ is the density $\left(19300 \mathrm{~kg} / \mathrm{m}^{3}\right)$, and $\mathrm{Cp}$ the specific heat $(\sim 130 \mathrm{~J} / \mathrm{kg}-\mathrm{K})$. This invokes an analogy to composite structural materials, where in this case we have an "aggregate" of small high- $Z$ particles embedded in a low- $Z$ "matrix". In principle, the task is much simpler than the designed of advanced structural composites: there are no constraints other than minimal self-support on mechanical strength.

\section{KINEMATIC MODEL}

Consider a simple energy-balance model that states the energy $E_{t h}$ available for thermal expansion is the total energy deposited in the material by the beam, less the total bonding energy. Given the proper material scale sizes, we will assume the different types of atoms in the composite are in local thermal equilibrium, and work in 
terms of energy per atom. Consider a composite of two materials, made of amounts equivalent to lengths $L_{H}$ and $L_{L}$ of pure high- and low- $Z$, respectively. For each material (with proper $\mathrm{H}$ or $\mathrm{L}$ subscript), denote the density by $\rho$, mass per atom $\mathrm{m}$, bonding energy per atom $E_{B}$, and energy deposition traditionally denoted as $\mathrm{dE} / \mathrm{dx}$ in units of energy per unit mass per unit area of material, per beam electron. Define the following dimensionless quantities: $\lambda=\rho_{\mathrm{L}} \mathrm{L}_{\mathrm{L}} / \rho_{\mathrm{H}} \mathrm{L}_{\mathrm{H}}, \quad \mathrm{M}=\mathrm{m}_{\mathrm{H}} / \mathrm{m}_{\mathrm{L}}, \mathrm{f}_{\mathrm{D}}=$ $(\mathrm{dE} / \mathrm{dx})_{\mathrm{L}} /(\mathrm{dE} / \mathrm{dx})_{\mathrm{H}}$ and $\mathrm{f}_{\mathrm{B}}=\mathrm{E}_{\mathrm{B}, \mathrm{L}} / \mathrm{E}_{\mathrm{B}, \mathrm{H}}$. If there were only a solid slab of pure high- $\mathrm{Z}$ material, the energy deposited per atom would be $E_{D, o}=\left(m_{H} I \tau d E / d x\right) /(A q)$ and the energy available $E_{0}=E_{D, 0}-E_{B, H}$, given an electron beam of current $I$, pulse length $\tau$, impinging on an area $A ; q$ is the electron charge. Normalizing to $E_{0}$ and defining a last dimensionless parameter $\varepsilon=\mathrm{E}_{\mathrm{B}, \mathrm{H}} / \mathrm{E}_{\mathrm{D}, \mathrm{o}}$,

$$
\frac{E_{t h}}{E_{o}}=\frac{\left(f_{D} \lambda+1\right)-\varepsilon\left(f_{B} M \lambda+1\right)}{(1-\varepsilon)(1+M \lambda)} .
$$

This expression reduces to 1 in the case of $\lambda=0$, no low-Z matrix; it can go negative, which in this simple two-state model simply means not enough energy has been added to break the bonds and allow thermal expansion. Consider a specific case of tantalum and carbon, $M=15$, and beam parameters corresponding to $E_{D, 0} \sim 12.5$. $E_{B}$ is estimated using integration of state equations [3] and gives $f_{D} \sim 1$ (strictly speaking it is a weak function of $\lambda$ ), $\varepsilon \sim 0.2, f_{B} \sim 0.6 . \lambda$ controls the ratio of the materials, which fixes the design because the amount of Ta is determined by the desired dose. A curve of $E_{t h} / E_{o}$ is shown in figure 1.

\section{HIGH-Z MATERIAL VELOCITY}

The energy curve looks highly favorable but is not the complete picture. The average thermal energy of the material can be been lowered considerably, but the average mass goes down as well and this leads to a higher average asymptotic expansion velocity. The question is, at what velocity does the high- $\mathrm{Z}$ (X-ray generating) material move? Let us look at two extreme cases. The first is the "ideal" case of no collisions between species, so that the high- $Z$ expands at its own thermal speed $v_{H} \sim\left(E_{t h} / m_{H}\right)^{1 / 2}$ based on the equilibrium energy. Unfortunately, for such a dense vapor or plasma state, there will be extensive collisions between the two materials. Consider the extreme of a single equilibrium velocity due to the collisional drag; the RMS thermal speed $v_{R M S}$ is the value that conserves total energy, and its value is high since it is weighted by the large number of low- $Z$ atoms. Normalizing both of these quantities to the no-matrix case $v_{0}=\left(E_{0} / m_{H}\right)^{1 / 2}$ gives the following expressions, graphed for the $\mathrm{Ta} / \mathrm{C}$ case in figure 1 .

$$
\frac{v_{H}}{v_{o}}=\sqrt{\frac{E_{t h}}{E_{o}}}, \frac{v_{R M S}}{v_{o}}=\sqrt{\frac{E_{t h}}{E_{o}} \frac{1+M^{2} \lambda}{1+M \lambda}} .
$$




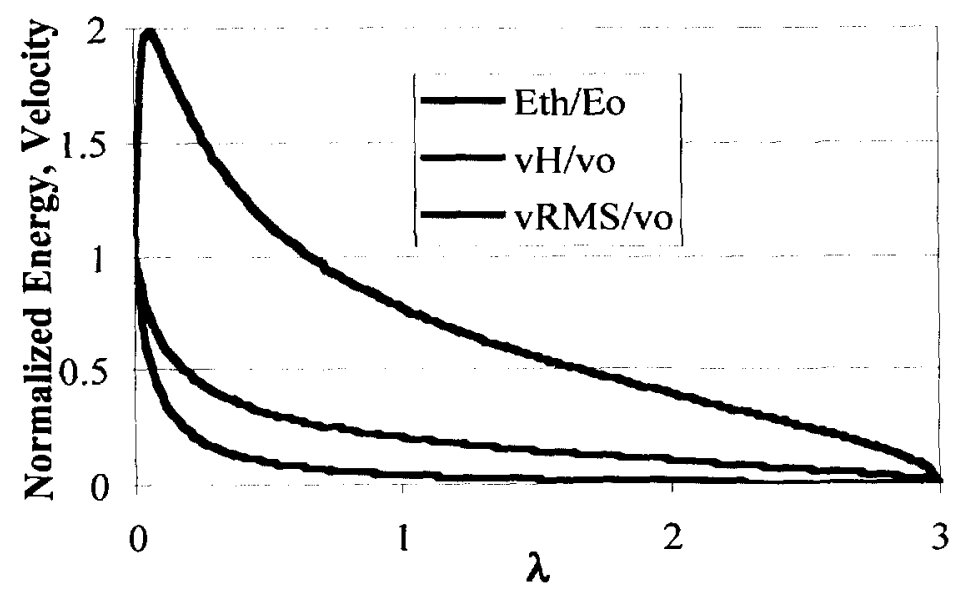

FIGURE 1. Sample curves of normalized energy and velocity for a mixture of Ta and C.

\section{CONCLUSIONS}

A composite mixture of high- and low- $Z$ materials reduces the asymptotic expansion velocity of converter target material by providing an "energy reservoir" in the form of a larger number of atomic bonds to be broken, while preserving dose relative to a solid high- $\mathrm{Z}$ target. Preliminary hydrodynamic modeling with the LASNEX code shows favorable agreement with the simple kinematic model given above [4]. Early experiments using visible-light imagine of expanding target plasmas also show favorable results, but have not clearly resolved the question of the expansion velocity of the high- $Z$ material. A number of material mixtures and manufacturing processes for achieving the requisite aggregate scale size will be tested at the ETA-II accelerator facility at Lawrence Livermore National Laboratory.

\section{ACKNOWLEDGMENTS}

This work was performed under the auspices of the U. S. Department of Energy by the University of California, Lawrence Livermore National Laboratory under Contract No. W-7405-Eng-48.

\section{REFERENCES}

1. M. J. Burns, et al., "DARHT Accelerators Update and Plans for Initial Operation," Proceedings of the 1999 Particle Accelerator Conference, New York, NY, 1999, pp. 617-621.

2. E. J. Lauer, "Materials that Resist Melting in Electron Beams," Beam Research Program Memo 89-13, Lawrence Livermore National Laboratory, Livermore, CA, 1989.

3. C. M. Snell, T. J. T. Kwan, "Photon Output for DARHT Beam Incident on Ta, Ta-Nb-V,and TaSi2 Target Foils," Los Alamos National Laboratory Research Note XTM-RN(U)99-004, Los Alamos National Laboratory, Los Alamos, NM, 1999.

4. D. D.-M. Ho, et al., "Target Studies for DARHT-II Multi-Pulse e-Beam Radiography," Proceedings of the $29^{\text {th }}$ IEEE Conference on Plasma Science, Banff, Alberta, Canada, 2002 